\title{
溶媒抽出／誘導結合プラズマ発光分光分析法による 天然水中微量タリウムの定量
}

\author{
(1991 年 7 月 31 日 受理) \\ 宮 崎 章* ·三瓶貴 弘 $^{\dagger}$ ・田尾博明 - 長瀬多加子 ${ }^{\dagger \dagger}$
}

\begin{abstract}
水中の微量タリウムを定量するために，試料中の T 1 を ammonium 1-pyrrolidinecarbodithioate (ammonium tetramethylenedithiocarbamate) (APDC) $と$ hexahydro- $1 H$-azepinium hexahydro$1 H$-azepine-1-carbodithioate (hexamethyleneammonium hexamethylenedithiocarbamate, HMA $\mathrm{HMDC}$ ) を用い 2,6-ジィチル-4-ヘプタノン (DIBK) に抽出し，T1 II $190.86 \mathrm{~nm}$ の波長を用い誘 導結合プラズマ発光分析法 (ICP-AES) で測定した。T 1 のスペクトルプロファイルは約 $190.855 \mathrm{~nm}$ と約 $190.867 \mathrm{~nm}$ にピークを示すが，これは T 1 の核スピンによる超微細構造であることがわかった。 DIBK に T 1 を抽出して ICP に導入した場合には, 溶媒中の炭素の影響と思われるバックグラウン ドの增大により妨害されるが，190.855 nm の波長で測定すれば直線の検量線が得られた。6 種類の共 存元素のち, Os と W について T 1 と重なる発光線が認められたが, 溶媒抽出後には Os(UII)は T 1 と同等量, W は少なくとも 40 倍量まで許容できた。濃縮倍率を 20 倍としたときの検出限界 $(3 \sigma)$ は $1.3 \mathrm{ng} / \mathrm{m} l$ で, $30 \mathrm{ng} / \mathrm{m} l$ に拈ける溶媒抽出操作を含めた相対標準偏差 $(n=10)$ は $5.4 \%$ であっ た。本法による NIST 標準試料 $1643 \mathrm{~b}$ の分析結果は保証値とよく一致した。また，国内のいくつか の河川水, 鉱内水, 温泉水から $15 \mathrm{ng} / \mathrm{m} l$ 以上の $\mathrm{T} 1$ が検出された。
\end{abstract}

\section{1 緒言}

タリウム（T 1) は古くから殺鼠剤や殺虫剤として用いられて きたが，近年では超電導材料や光学レンズ，人工宝石などにも用 いられるよ5になった1)2)。しかし，その毒性は高く，米国環境保 護庁（USEPA）の水質基準でも水および水生生物を摂取する場 合 $13 \mu \mathrm{g} / l$, 水生生物のみを摄取する場合 $48 \mu \mathrm{g} / l$ といら低い 濃度となっている3)。また，1989年 3 月には，国連環境計画 (UNEP) において産業廃率物関連の有害物質として T 1 なども 指定しよらとする国際条約（バービル条約）が採択されており， 今後国内においても有害物質として指定される可能性がある。

環境試料中の T 1 は一般に天然の存在量が低いため, これまで フレームレス原子吸光法年5), アノディックボルタンメトリー6),

資源環境技術総合研究所水圏環境保全部, 305 つくば市 小野川 16-3

†北里大学衛生学部 228 相模原市北里 1-15-1, 現在大東 銀行, 978 福島県石川町

${ }^{\dagger \dagger}$ 現在東北工業技術試験所，983 仙台市宮城野区苦竹4-2-1

1) V.Zitko, The Science of Total Environment, 4, 185 (1975).

2）浅見輝男，科学々思想， 1989，705.

3）荒木 峻, 沼田 真, 和田 攻編, “環境化学辞典”, 東京 化学同人 (1985) p. 899 .

4) J. P. Riley, S. A. Siddiqui, Anal. Chim. Acta, 181, 117(1986).

5) A. Ruck, C. Vandecasteele, R. Dams, Mikrochim. Acta, 2, 187(1987).
同位体希釈質量分析法 ${ }^{718)}$ などで測定された例はあるが，誘導結合 プラズマ発光分析法 (ICP-AES) で天然水中の濃度を測定した例 はほとんど報告されていない。

ICP-AES において最も感度が高いT 1 の分析線はイオン線の $190.86 \mathrm{~nm}$ であることが知られている。著者らは先に溶媒抽出/ ICP-AES による水中のタリウム, ビスマス, インジウムの定量

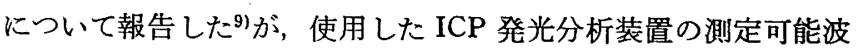
長範囲の下限に近かったため, $190.86 \mathrm{~nm}$ での高感度測定は困難 であった。そこで, 今回, 真空分光器を使用して $190.86 \mathrm{~nm}$ 付 近での測定を行い, スペクトルプロフィルの分光学的特性, 共存 元素の影響などを検討した。また, 溶媒抽出法で T 1 を濃縮した 後, 日本各地から採取した水試料を分析した。

\section{2 実験}

\section{1 装置}

ICP 発光分析装置はセイコー電子工業 SPS $1200 \mathrm{~V}$ 型を使用し た。表 1 に, T 1 の水溶液を直接分析する場合と 2,6-ジメチルー 4-ヘプタノン（ジイソブチルケトン, DIBK）に溶媒抽出して分 析する場合のそれぞれの最適操作条件を示す。

なお, ICP-AES で得られた分析結果の確認のために島津製作

6) J.M. Kauffmann, T.H. Montenez, J. L. Vardenbalck, G. J.Patriache, Mikrochim. Acta, 1, 95(1984).

7）室住正世, 五十京竜志, 中村精次, 日化, 1982, 54.

8) J. Trettenback, K. G. Heumann, Z. Anal. Chem., 322, 306(1985).

9）高橋 徽, 宮崎 章, 番匠蜸治, 公害, 22,330(1987). 
Table 1 Optimum experimental conditions for ICP measurement

I.c.p. instrument

Seiko $1200 \mathrm{~V}$

Operating frequency

$27 \mathrm{MHz}$

Nebulizer

Focal length of spectrometer

Grating

Entrance slit width

Exit slit width

Slit height

Reciprocal linear dispersion

Concentric

$1.0 \mathrm{~m}$

3600 line $/ \mathrm{mm}$, Holographic

$20 \mu \mathrm{m}$

$40 \mu \mathrm{m}$

$4 \mathrm{~mm}$

$0.22 \mathrm{~nm}$ (at $270 \mathrm{~mm}$ )

Aqueous solution DIBK extract

Operating power

$1.1 \mathrm{~kW}$

$1.4 \mathrm{~kW}$

Argon flow rates

coolant

auxiliary

carrier

$16 \mathrm{l} / \mathrm{min}$

$0.3 \mathrm{l} / \mathrm{min}$

$2.0 \mathrm{~kg} / \mathrm{cm}^{2}$

$12 \mathrm{~mm}$

above load coil
スペクトルプロファイルが図 1 のよらな分裂を示寸原因として は電子の軌道運動量やスピン角運動量に起因与るエネルギー準位 の分裂によるもののほかに，原子核の同位体効果あるいは核スピ ンがあることはよく知られている11。そこで，図 1 の場合につい て上記のどれが分裂の原因と考えられるかを検討した。

先ず, 軌道電子のエネルギー值 ${ }^{12}$ からグロトリアン図を作成 し，選択則を考虑しながら図 1 の二つのピーク波長に相当する遷 移があるかどうかを調べたが，該当する遷移は認められなかっ た。このことは電子の軌道運動量やスピン角運動量によるもので はないことを示している。

次に, T 1 の濃縮同位体(米国オークリッジ国立研究所製 ${ }^{203} \mathrm{~T} 1$, $\left.0.56 \%,{ }^{205} \mathrm{~T} 1,99.44 \%\right)$ と天然の T1 スペクトルプロフィル を比較したが，図 2 に示すようにほとんど同一のプロフィルが得 られた。したがって，同位体効果の可能性もないと考えられる。

一方, 核スピン $I$ は電子の全角運動量 $J$ と結合して, 新たな角 運動量 $F$ を生ずる。この時, $F$ は $J+I, J+I-1, J+I-2 \cdots$

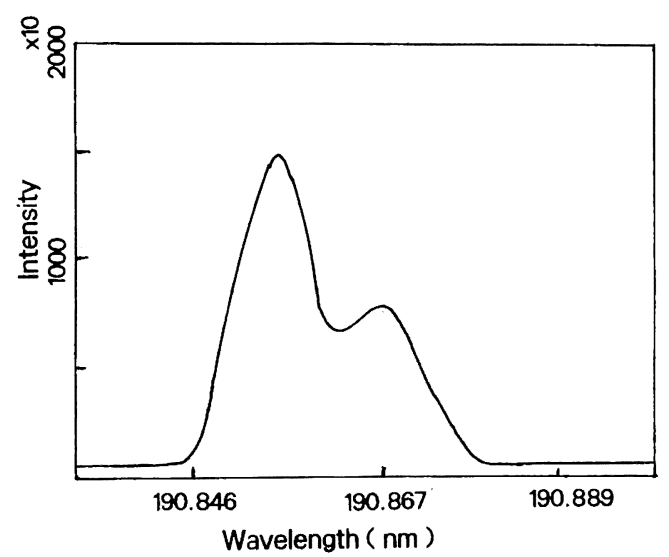

Fig. 1 Spectral profile of T 1 II $190.86 \mathrm{~nm}$ for aqueous solution containing $5 \mathrm{mg} / \mathrm{l}$ of $\mathrm{T} 1$

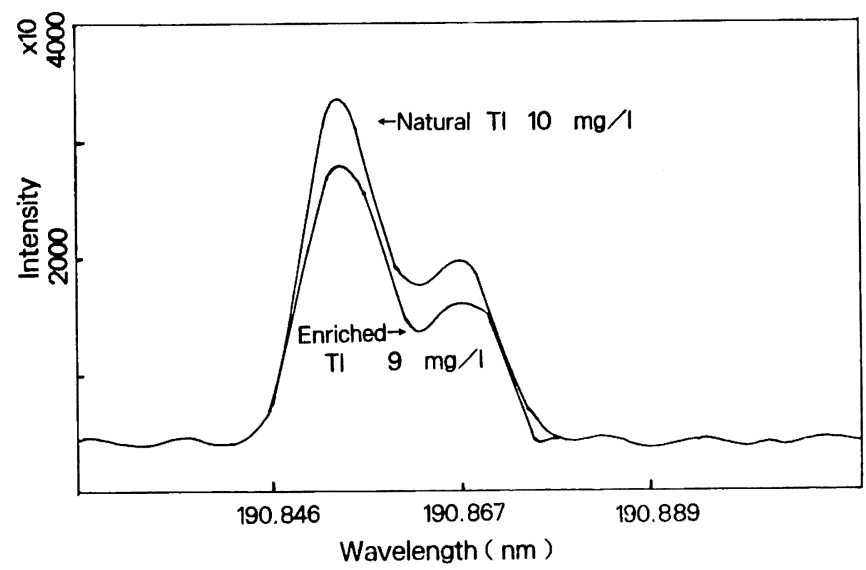

Fig. 2 Spectral profiles of $\mathrm{T} 1$ with different isotopic composition

11）原口紘帒, 大道寺英弘, 中原武利編, “原子スペクトル测 定と応用”, 学会出版センター (1989) p. 21.

12) C. H. Moore, “Atomic Energy Levels Vol. III" NBS Washington D.C. U.S.A (1958), p. 204. 


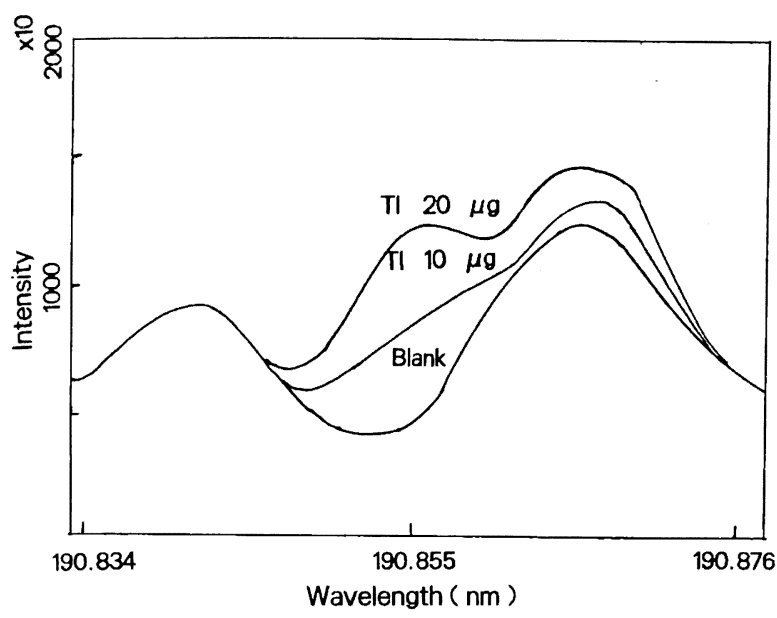

Fig. 3 Spectral profile of $\mathrm{T} 1$ extracted in DIBK

$|J-I|$ の值をとり，選択則は $\Delta F=0, \pm 1$ である ${ }^{11)}$ 。 T 1 $190.86 \mathrm{~nm}$ の遷移は ${ }^{3} \mathrm{P}_{1} \rightarrow{ }^{1} \mathrm{~S}^{12)}$ で, T 1 の核スピンは質量数 203，205 ともに $1 / 2^{13)}$ であるから， ${ }^{1} \mathrm{~S}_{0}$ では $F=1 / 2,{ }^{3} \mathrm{P}_{1}$ では $F=3 / 2,1 / 2$ となる。したがって, $F=3 / 2$ から $1 / 2$, 並びに $1 / 2$ から $1 / 2$ の癸移則にも適合するから, T $1190.86 \mathrm{~nm}$ のスペクト ル線は 2 本のピークをもつ超微細構造を与えることになる。

以上に述べたスペクトル線の分裂の様子からもわかるように， $\mathrm{T} 1$ の水溶液では $190.855,190.861 \mathrm{~nm}$ のどちらの波長で測定し ても定量が可能であると結論される。

次に溶媒抽出を適用した場合について検討するために T 1 の DIBK 溶液のスペクトルプロファイルを調べた。図 3 に示すよ らに有機溶媒導入時も水溶液と同様に二つのピークが認められる が， $190.867 \mathrm{~nm}$ の波長では，溶媒中の炭素之思われるピークに 妨害される。しかし，190.855 nm の波長で測定すれば，T 1 の量 の変化に応じて発光強度も変化しているので, 定量が可能であっ た。

また，T 1 には天然で安定な酸化数としてＩ洒と価がある が，既報9で述べたように $\mathrm{pH} 6$ で抽出すれば T 1( I ) と T 1 （III）の両方がほぼ 100\% 抽出されるため, 本法により水中の無 機態 T 1 の全量を定量できると考えられる。

\section{2 検量線, 検出限界及び精度}

2.3 の操作によって DIBK 層に抽出した後, DIBK 層をブラ ズマ中に直接に導入して，190.855 nm で測定した場合の検量線 は，原点を通り，少なくとも試料中の濃度として $625 \mathrm{ng} / \mathrm{ml}$ まで 直線となり，検出限界 $(3 \sigma)$ は $1.3 \mathrm{ng} / \mathrm{ml}$ であった。

な扰，T 1 の水溶液を導入した場合の検出限界（3 $\sigma)$ は 16 $\mathrm{ng} / \mathrm{ml}$ であった。

また, T 1 濃度 $30 \mathrm{ng} / \mathrm{ml}$ の試料に対して溶媒抽出操作を含め て10 回の繰り返し分析を行った場合の分析值の相対標準偏差は $5.4 \%$ であった。

\section{3 共存元素による分光干涉}

T 1 II 190.86 nm 付近での共存元素による分光干渉を検討する ため，まず，T $15 \mu \mathrm{g} / \mathrm{m} l$ と共存元素 $200 \mu \mathrm{g} / \mathrm{m} l$ を含む水溶液を 調製し，それらのスペクトルプロファイルを倹討した。共存元素

13） G. Herzberg 著, 堀 健夫訳，“原子スペクトルと原子構 造”, 丸善, (1971) p. 207.
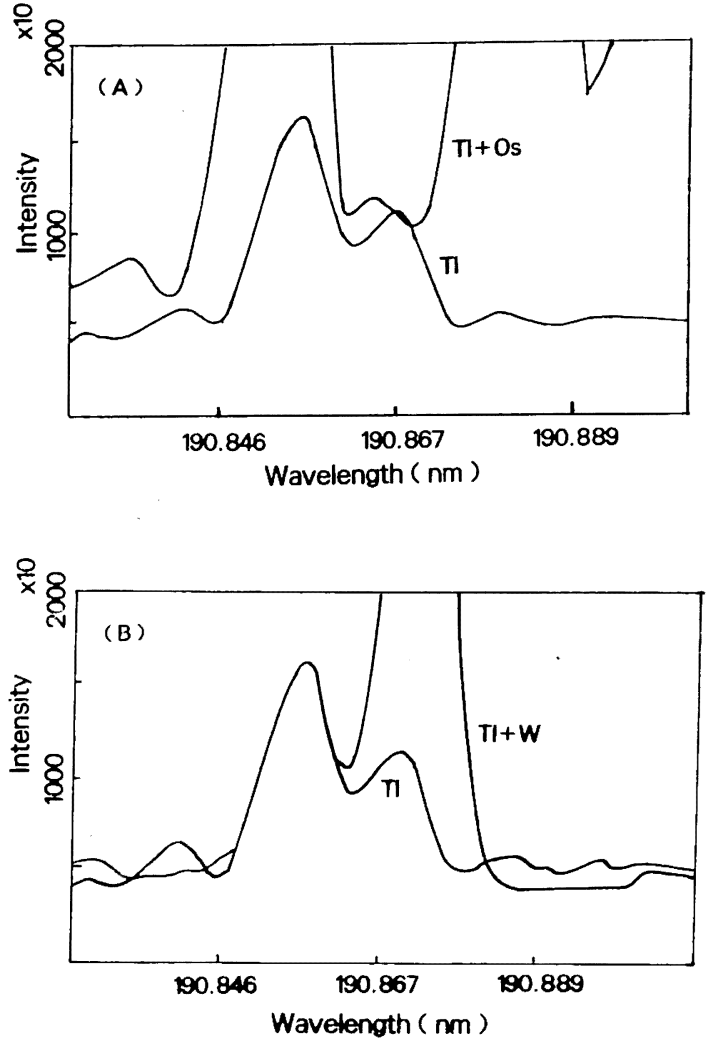

Fig. 4 Spectral coincidence profiles for aqueous solutions containing $5 \mathrm{mg} / \mathrm{l}$ of $\mathrm{T} 1$ and $200 \mathrm{mg} / l$ of $\mathrm{Os}(\mathrm{A})$ or W(B)

としては周期表の $\mathrm{Li}$ から $\mathrm{Bi}$ までの元素のうち $\mathrm{C}, \mathrm{N}, \mathrm{O}, \mathrm{F}$, $\mathrm{Ne}, \mathrm{Cl}, \mathrm{Ar}, \mathrm{Br}, \mathrm{Kr}, \mathrm{Tc}, \mathrm{Ru}, \mathrm{Rh}, \mathrm{Pd}, \mathrm{I}, \mathrm{Xe}, \mathrm{Hf}, \mathrm{Pm}$ を除 く63 種類の共存元素について調べた。その結果, T 1 の分析線 近傍の $190.840 \sim 190.900 \mathrm{~nm}$ の範囲において Mo (190.872 $\mathrm{nm}), \mathrm{Ce}(190.844 \mathrm{~nm})$, Ta $(190.880 \mathrm{~nm})$, Os $(190.855 \mathrm{~nm}$, $190.888 \mathrm{~nm}), W(190.871 \mathrm{~nm})$ の溶夜では, それぞれカッコの 中に示した波長の発光線が認められた。これらの発光線は既存の 波長表 ${ }^{14) ~ 16)}$ には記載されていない。このらち T 1 の発光線と重 なるピークを示した Os とWのスペクトルプロファイルを図 4 に 示す。

2.3 で述べた溶媒抽出法を用いると上記の T1 の発光線近傍に 発光線を有する元素のうち, Ce 以外の元素は抽出されるが ${ }^{17}$, Os は T 1 と同等量, Wは少なくとも 40 倍量まで共存しても T 1 の分析値はこれらの元素が共存しない場合に比べて $5 \%$ 以内 の䛊差で一致した。なおここで検討した Os は原子洒が笑価で あった。Os (VII) は揮発性のため ICP への導入率が高く, 水中 の濃度が同じでも他の原子価の Os にくらべて約 50〜100 倍発光

14) D. D. Nygaard, D. A. Leighty, Appl. Spectrosc., 39, 968(1985).

15）日本分光学会編，“ICP スペクトル写真集”，丸善，（1986） p. 84.

16) R. L. Kelly, "Atomic and Ionic Spectrum Lines below 2000 Angstoms Part I III" Analytical Chemical Society, American Institute of Physics, National Bureau of Standards, U.S.A. (1987).

17) H. Tao, A. Miyazaki, K. Bansho, Anal. Sci., 1, 169 (1985). 
Table 2 Analytical results of environmental waters

\begin{tabular}{|c|c|c|c|}
\hline \multirow{2}{*}{\multicolumn{2}{|c|}{ Sample }} & \multicolumn{2}{|c|}{ Concentration $(\mathrm{ng} / \mathrm{m} l)$} \\
\hline & & ICP & AAS \\
\hline \multicolumn{4}{|c|}{ River $\mathrm{A}^{a)}$} \\
\hline (1) & Collected in Oct. 1980 & $270 \pm 10^{e)}$ & $250 \pm 12$ \\
\hline (2) & Collected in Oct. 1989 & $180 \pm 8$ & $170 \pm 8$ \\
\hline (3) & Collected in Sep. 1990 & $28 \pm 1$ & $30 \pm 2$ \\
\hline \multicolumn{4}{|c|}{ Mine $B^{b)}$} \\
\hline (1) & & $15 \pm 0.6$ & n.d.c) \\
\hline (2) & & $23 \pm 0.8$ & n.d. c) \\
\hline (3) & & $160 \pm 7$ & $160 \pm 6$ \\
\hline (4) & & $55 \pm 2$ & $60 \pm 4$ \\
\hline (5) & & $76 \pm 3$ & $83 \pm 5$ \\
\hline \multicolumn{4}{|c|}{ Hotspring $\mathrm{C}^{d}$ ) } \\
\hline \multicolumn{2}{|c|}{ (1) } & $33 \pm 2$ & $35 \pm 8$ \\
\hline a) & \multicolumn{3}{|c|}{$\begin{array}{l}\text { Samples were collected at the same place of the } \\
\text { river } A \text { in different years. }\end{array}$} \\
\hline$b)$ & \multicolumn{3}{|c|}{$\begin{array}{l}\text { Samples were collected from the different places } \\
\text { of the mine B on Sep. 25, } 1988 \text {. }\end{array}$} \\
\hline c) & \multicolumn{3}{|c|}{ Not detected. } \\
\hline$d)$ & \multicolumn{3}{|c|}{ Sample was collected on Oct. 15, 1989.} \\
\hline e) & \multicolumn{3}{|c|}{ Mean and standard deviation of five measurements. } \\
\hline
\end{tabular}

Table 3 Analytical results of ore samples collected from a mine beside the river $A$

$\begin{array}{ccc}\text { Sample } & \text { Concentration of } \mathrm{T} 1(\mu \mathrm{g} / \mathrm{g}) \\ \text { ICP } & \text { A AS } \\ \text { A } & 70.9 \pm 3.6^{a} & 71.4 \pm 5 \\ \text { B } & 17.4 \pm 1.0 & 16.8 \pm 0.8 \\ \text { C } & 8.8 \pm 0.6 & \left.\text { n.d. }{ }^{b}\right) \\ \text { D } & 11.4 \pm 0.5 & 11.2 \pm 2.8 \\ \text { E } & 6.1 \pm 0.3 & \text { n.d. } \\ \text { F } & 0.6 \pm 0.05 & \text { n.d. }\end{array}$

a) Mean and standard deviation of three measurement.

b) Not detected.

強度が高くなる ${ }^{18)}$ 。一般に天然水中では Os, W の濃度が低く, Os が证価で存在することも少ないと考えられるため, 本法を適 用してもほとんどの試料の場合これらの元素のスペクトル干渉は ないと考えられる。

18) H. Tao, A. Miyazaki, K. Bansho, Anal. Chem, 60, 1762(1988).

\section{4 実試料の分析}

本法の正確さを検討するために, NIST 標準試料 1643 b (Trace Element in Water) 中の T 1 を分析し保証值と比較し た。本法による平均值は $7.7 \pm 0.4 \mathrm{ng} / \mathrm{ml}(n=5)$ となり, 保証值 $8.1 \pm 0.2 \mathrm{ng} / \mathrm{m} l$ とよく一致して扣り, 本法によれば正確な分析 值が得られることが確認できた。

本法を用いて, 国内各地の, 河川水, 鉱内水, 温泉水の $\mathrm{T} 1$ を 分析した。また, 比較のために 2.3 の抽出操作を行った後, フレ 一ム原子吸光法でも測定を行った。表 2 に本法の定量下限（ブラ ンク溶液の発光強度の標準偏差の 10 倍, すなわち $10 \sigma$ に相当 する濃度とした）より高い濃度を示した試料の分析值を示す。

このうち河川水 $\mathrm{A} の 1980$ 年, 1989 年採取の試料で高い濃度の T 1 が検出された原因を検討するために, 河川水の採取地点の上 流にあり, 現在は休廃止鉱山となっている鉱山の鉱石を酸分解し て T 1 の濃度を調べた。表 3 に示すようにかなり高い浱度で T 1 が認められたことから,この鉱山の存在が河川 AのT 1 と何ら かの関連をもつことも考学られる。

\section{4 結言}

環境水中の T 1 を APDC と HMAHMDC を用いて DIBK 中に溶媒抽出し，T 1 II $190.86 \mathrm{~nm}$ の発光線により定量する方法 を検討した結果, 次のことがわかった。

1. T1 II $190.86 \mathrm{~nm}$ のスペクトルプロファイルは, 190.855 $\mathrm{nm}$ と $190.867 \mathrm{~nm}$ の二つのピークに分裂するが，これは原子核 スピンに起因する超微細構造であると考えられる。

2. DIBK に抽出した T 1 を ICP に導入した場合には $190.867 \mathrm{~nm}$ の波長では溶媒中の炭素と思われるピークに妨害さ れるが， $190.855 \mathrm{~nm}$ の波長で測定すれば直線の検量線が得られ る。

3. 本法を NIST 標準試料 (1643 b) の分析に適用した結果, 保証值と一致した值が得られ，本法の実用性が高いことがわかっ た。また, 国内各地から採取した水試料を分析した結果, いくつ かの試料について, $10 \mathrm{ng} / \mathrm{m} l$ レベル以上の $\mathrm{T} 1$ が検出された。

T 1 の波長についての資料を戴いた国立環境研究所化学環境 部, 古田直紀氏, 化学技術研究所化学標準部 久保田正明氏, 尘 た, 鉱石試料を提供して戴いた東北大学理学部 大本洋教授に 深く感謝致します。 


\title{
Determination of Trace Thallium in Natural Waters by Inductively Coupled Plasma Emission Spectrometry Combined with Solvent Extraction
}

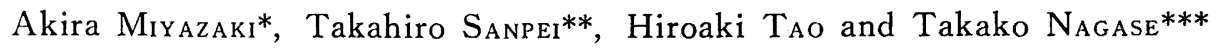 \\ National Intistute for Resources and Environment, 16-3, \\ Onogawa, Tsukuba, Ibaraki 305 Japan \\ ** School of Hygienic Sciences, Kitasato University ; \\ 1-15-1 Kitasato, Sagamihara, Kanagawa 228 Japan \\ Pre ent address; Daito Bank, Ishikawa, Fukushima' 978 Japan \\ *** Present address; Government Industrial Research Institute, Tohoku; \\ 4-2-1, Nigatake, Sendai-shi 983 Japan
}

Determination of $\mathrm{Tl}$ in water by inductively coupled plasma emission spectrometry after solvent extraction was investigated at T 1 II $190.86 \mathrm{~nm}$. The spectral profile of the emission line of T1 showed two peaks at 190.855 and $190.867 \mathrm{~nm}$. The reason of the profile split was concluded to be a superfine structure due to the nuclear spin. The spectral profiles obtained for aqueous solutions with $5 \mu \mathrm{g} \mathrm{Tl} / \mathrm{m} l$ and $200 \mu \mathrm{g} / \mathrm{m} l$ each of diverse elements revealed that Mo, Ce, Ta, Os and $\mathrm{W}$ had emission lines close to the Tl $190.86 \mathrm{~nm}$ line, which were not stated in the conventional wavelength tabled. When $\mathrm{Tl}$ was extracted into 2,6-dimetyl-4heptanone (DIBK) after complexation with ammonium 1-pyrrolidinecarbodithioate (APDC) and hexahydro- $1 \mathrm{H}$-azepinium hexahydro- $1 \mathrm{H}$-azepine-1-carbodithioate (hexamethyleneammonium hexamethylenedithiocarbamate) (HMAHMDC), measurement at $190.855 \mathrm{~nm}$ was successful, although the $190.867 \mathrm{~nm}$ emission line suffered from the increase of background intensity presumably due to carbon in DIBK. With $160 \mathrm{~m} l$ of water sample and $8 \mathrm{~m} l$ of DIBK, the detection limit $(3 \sigma)$ was $1.3 \mathrm{ngTl} / \mathrm{m} l$ in original samples, and the calibration curve was linear up to $625 \mathrm{ng} / \mathrm{m} l$. The relative standard deviation $(n=10)$ including the solvent extraction process for $30 \mathrm{ngTl} / \mathrm{m} l$ was $5.4 \%$. Among the diverse elements, Os(VII) more than the concentration of $\mathrm{Tl}$, and $\mathrm{W}$ more than 40 times the concentration of $\mathrm{Tl}$ caused spectral interferences even after the solvent extraction. Since Os and $\mathrm{W}$ are usually rare in waters, the proposed method was successfully applied to the analysis of river, mine and hotspring waters. Some samples contained $15 \mathrm{ng} / \mathrm{m} l$ or more of $\mathrm{Tl}$. 